hazard relates to wood dusts generally or only to the dusts from specific woods.

In other parts of the world, notably China, Malaysia, Indonesia, and East Africa, nasopharyngeal cancer is more frequent than in the United Kingdom. ${ }^{3}$ It seems unlikely, however, that the aetiological factors in these areas, such as incense smoke, smoke from domestic wood fires, ${ }^{5}$ and racial, $^{6}$ anatomical, ${ }^{7}$ nutritional, ${ }^{7}$ or possibly hormonal ${ }^{8}{ }^{9}$ factors, affect furniture makers in the Oxfordshire and Buckinghamshire area of England, and Acheson and his colleagues have virtually excluded snuff-taking ${ }^{10-12}$ as a factor. According to C. A. Linsell ${ }^{13}$ and S. Yeh ${ }^{14}$ only a small minority of the nasopharyngeal cancers in Kenya are adenocarcinomas, and in China the epidermoid type of tumour is even more predominant. Other agents known to cause nasopharyngeal cancer in man, notably nickel, radium, and isopropyl alcohol, have no place in furniture manufacture, and the only possibly relevant lead from the laboratory at present is the discovery that tumours of a variety of histological types, including adenocarcinoma, may be induced in the nasal cavities of rats by exposure to certain nitrosamines, ${ }^{15}{ }^{16} \mathrm{~N}, N^{\prime}-2,7$-fluorenylenebisacetamide, ${ }^{17}$ or polyoma virus. ${ }^{18}$

After a preliminary report by Acheson and his colleagues ${ }^{19}$ a possible association between woodworking occupations and death from Hodgkin's disease was reported. ${ }^{20}$ Acheson, ${ }^{21}$ however, was unable to find a similar association in relation to his material.

The replacement of the skilled craftsman by machinery and the introduction of ventilation to extract dust in larger factories has transformed the furniture industry during the past 30 years, so that the hazards to health are now probably very different from what they were before the war. It is therefore a matter of urgency that further studies as careful as that of Acheson and his colleagues, but on different furniture-making communities, be undertaken in order to detect more precisely the carcinogen or carcinogens at work.

\section{Care and Training of Handicapped Children}

It has often been said that a sensitive index of any nation's level of cultural development is the provision it makes for its handicapped children. Britain makes the proud claim that in this respect it leads the world.

A recent number of Medical and Biological Illustration ${ }^{1}$ is devoted to a review of existing provisions for the diagnosis, treatment, supervision, and education of handicapped children from early childhood to school-leaving age. The issue includes papers on the role of a developmental-paediatrics centre and on schools for children suffering from blindness, impaired hearing, deafness with maladjustment, delicate children, and children with physical handicaps of various sorts, including a hospital school for children with epilepsy. There is also a delightful paper on gardening as an appropriate hobby for handicapped children, who tend to spend too much of their lives indoors. It concludes with an editorial, a list of recommended readings, and a selection of book reviews. The illustrations are admirably chosen and splendidly produced.

Taken as a whole, the collection of papers raises a number of questions still open to discussion about the changing views of educational experts, school medical officers, and paediatric consultants on special educational treatment. At the beginning of the century, when special schools first came into existence, the cure or mitigation of some clearly defined handicap was the first thought, so that attention was concentrated on treating the disorder, sometimes at the expense of the child's education. Later, the child's developing personality and intellect received more attention, but the presenting handicap still got priority in his education. But during the past decade it has increasingly been recognized that careful evaluation and training of the child's individual assets are of paramount importance at school and in life. It is generally agreed that, while the proportion of handicapped children requiring special arrangements remains much the same as formerly, the nature of their handicaps (and therefore their needs) is more complicated. Medical progress, which has prevented or cured many conditions which formerly necessitated extensive special educational provisions, has also kept alive many children with more severe and complex multiple handicaps who formerly would have died. In one sense it may be argued that every handicapped child, whatever his presenting disability, is multi-handicapped, because he is at a disadvantage socially, emotionally, or intellectually. But there is no doubt that the existing list of more or less mutually exclusive categories of handicaps has become unrealistic. There seems, therefore, to be a strong case for a detailed review of the whole question of formal ascertainment for special education and for a fresh look at the special schools themselves. Since he must eventually live in the ordinary community, a handicapped child should if possible attend an ordinary school, but this may not always be practicable for educational, social, or geographical reasons. These may not always be apparent to uninformed people, including the child's own family.

The first need is for improved diagnostic services, so that any child suspected of deviating from the normal course of physical, intellectual, emotional, or social development may be provided with the special treatment he requires at the most appropriate stage. Specially designed buildings, though essential for certain groups of handicapped children, are not so important as specially trained and experienced teachers, educational psychologists, and school medical officers, all of whom are scarce. It is doubtful if more special schools are needed, but more special day centres and classes attached to ordinary schools are. They should be provided for children of all ages, beginning with nursery units for children from 3 years upwards. In these units it would be possible not only to study the children's individual needs more completely, but also to give the parents better guidance on home management and to keep them completely informed about the child's progress and what plans should be made for his future.

When a child must be educated away from home every effort should be made to send him home for week-ends and to return him to a suitable day school as soon as possible. Family doctors and school medical officers concerned should consider it a duty to maintain relations with him and his family during holidays, and, when he returns to the ordinary school, to make sure that he is adequately followed up. Finally, it must always be kept in mind that the finest diagnostic provisions are of little use to any handicapped child or to his parents unless the appropriate welfare services are always readily available to them.

\footnotetext{
' Med. biol. Ill., 1967, 17, No. 4.
} 